http://dx.doi.org/10.1029/2008GL033286

(c) 2008 American Geophysical Union

An edited version of this paper was published by $\underline{A G U}$.

\title{
Helium isotopes on the Pacific-Antarctic ridge $\left(52.5^{\circ}-41.5^{\circ} \mathrm{S}\right)$
}

\author{
Manuel A. Moreira ${ }^{1,{ }^{*}}$, Laure Dosso ${ }^{2}$ and Hélène Ondréas ${ }^{3}$
}

${ }^{1}$ Institut de Physique du Globe de Paris, Equipe de Géochimie et Cosmochimie, Université Paris Diderot et CNRS UMR7154, Paris, France

${ }^{2}$ CNRS, UMR6538, Domaines Océaniques, IFREMER, Plouzané, France

${ }^{3}$ IFREMER, Plouzané, France

*: Corresponding author : M. Moreira, email address : moreira@ipgp.jussieu.fr

\begin{abstract}
:
The first isotopic data and concentrations of helium are reported for the Pacific-Antarctic ridge between $52.5^{\circ} \mathrm{S}$ and $41.5^{\circ} \mathrm{S}$. The ${ }^{4} \mathrm{He} /{ }^{3} \mathrm{He}$ ratio is extremely homogeneous over more than $1200 \mathrm{~km}$, with a mean ratio of 99,275 $(\mathrm{R} / \mathrm{Ra}=7.29)$ and a standard deviation of $2719(0.19)$, which is the lowest dispersion observed for the global mid oceanic ridge system. Moreover, the Menard T.F. is a frontier between two mantles with slightly different helium isotopic ratios $(96,595 \pm 1520$ and 100,347 \pm 2330$)$. No difference in the helium concentration between the two ridge segments defined by the Menard T.F. can be observed, as well as no significant difference in the $U$ and Th contents suggesting that the difference in helium isotopic ratio is old (>500 My) and may represent a slight difference in degassing or/and trace element depletion history.
\end{abstract}

Keywords: helium isotopes; mantle geochemistry; Pacific-Antarctic ridge. 


\section{Introduction}

One important tool to constrain the nature and origin of mantle heterogeneities is the helium isotopic ratio. The Mid Oceanic Ridge Basalts (MORB) sample an apparent homogeneous reservoir, that is radiogenic compared to most of the oceanic island basalts (OIB). The mean MORB ${ }^{4} \mathrm{He} /{ }^{3} \mathrm{He}$ ratio is $90,000 \pm 10,000$ [Allègre et al., 1995], or $\mathrm{R} / \mathrm{Ra}=8 \pm 1$ when using the ${ }^{3} \mathrm{He} /{ }^{4} \mathrm{He}$ notation with $\mathrm{Ra}$ being the atmospheric ratio $\left(=1.38410^{-6}\right)$. OIB show helium ratio between 18,000 and more than 150,000 [Allègre et al., 1995 ; Hilton et al., 1999 ; Moreira et al., 1999; Stuart et al., 2003 ]. The lower than MORB ratios are often interpreted in terms of the presence of a primitive reservoir, i.e. less degassed [Kurz et al., 1982] [Allègre and Moreira, 2004]. As a matter of fact, the ${ }^{4} \mathrm{He} /{ }^{3} \mathrm{He}$ ratio reflects the timeintegrated $(\mathrm{U}+\mathrm{Th}) /{ }^{3} \mathrm{He}$ ratio. To preserve low ${ }^{4} \mathrm{He} /{ }^{3} \mathrm{He}$ ratios, it is therefore necessary to have either higher ${ }^{3} \mathrm{He}$ or lower $\mathrm{U}+\mathrm{Th}$ concentrations. Most OIB present enriched trace element patterns that suggest that OIB source contain more $U$ and Th than the depleted MORB source. Therefore the most common interpretation for the helium distribution is the presence of a degassed MORB source and of some primitive (non degassed) reservoirs, certainly located in the lower mantle, that are sampled by mantle plumes.

Most of the ridge segments are influenced by hotspots, attributed to mantle plumes reaching the surface (e.g. Iceland, Azores, Shona, Discovery in the Atlantic, Marion, Croset, St Paul-Amsterdam in the Indian Ocean, Easter Island, Galapagos in the Pacific, ...). This "plume-ridge" interaction may have an influence on isotopic ratios and trace element signatures on distances larger than few hundreds of kilometers [Schilling, 1985; Schilling, 1991]. Only few ridge segments are not influenced by hotspots and none were studied in the Pacific for helium. Our new collection of samples allows a description of the mantle beneath the Pacific-Antarctic ridge far from any hotspot.

\section{Sample locations and analytical procedure}

PACANTARCTIC2 was a joint geophysical survey and geochemical sampling cruise to the PacificAntarctic Ridge between $41^{\circ} 15^{\prime} \mathrm{S}$ and 52 $45^{\prime}$ 'S. From December 17, 2004 to January 17,2005, the French research vessel L'Atalante surveyed 1300 kilometers of the pacific-Antarctic Ridge axis and made $3200 \mathrm{~km}$ of off-axis profiles to describe the structures located on either side of the Menard T.F. and west of the axis at $42^{\circ} \mathrm{S}$. During the cruise, 43 dredges were performed among which 24 were on axis. We are focusing on these on-axis dredges on this paper [Dosso et al., 2005] (Figure 1). Details about ridge structure and sample chemistry can be found in [Klingelhoefer et al., 2006] and in [Hamelin et al., 2007].

Pieces of glass, $\sim 0.5 \mathrm{~cm}$ in size, were cleaned with distilled water, ethanol and acetone using an ultrasonic bath. Some samples were also cleaned with hydrogen peroxide in order to remove some Mn crust. Twelve glass samples with weights between 0.1 and $0.7 \mathrm{~g}$ were loaded in a glass sample tree connected to the Staudacher-type glassy High frequency furnace equipped with a Mo crucible. Sample were melted at $\sim 1400^{\circ} \mathrm{C}$ in order to degas. Gas was purified with two titanium getters at $800^{\circ} \mathrm{C}$ during 10 minutes each. Furnaces were then stopped to decrease the Ti getter temperature to room temperature during 10 minutes. $\mathrm{H}_{2}$ was purified with two SAES getters at room temperature. Rare gases were then trapped at $10 \mathrm{~K}$ on charcoal trap. Helium was desorbed at $25 \mathrm{~K}$ and then analyzed. Helium concentrations and the isotopic ratios were measured with our mass spectrometer ARESIBO II, equipped with a faraday cup for ${ }^{4} \mathrm{He}$ and a electron multiplier connected to an ion counting system for ${ }^{3} \mathrm{He}$. An aliquot of the helium was generally kept and analyzed immediately after the first helium measurement to confirm this analysis. In all cases, the duplicate gave the same isotopic ratio (within \pm 0.1 on the $\mathrm{R} / \mathrm{Ra}$ ratio). Blanks were analyzed before each sample by heating the furnace at the same temperature as the samples. The ${ }^{4} \mathrm{He}$ blank was $\sim 10^{-8} \mathrm{ccSTP}$, which generally corresponds to less than $1 \%$ of the measured helium. For these analyzes, we have modified our old helium procedure for which ${ }^{3} \mathrm{He}$ was measured at mass $3.016 .{ }^{3} \mathrm{He}$ is now measured at mass 3.014 , where the $\mathrm{HD}^{+}$correction is negligible for low $\mathrm{H}_{2}$ signals. The $\mathrm{H}_{2}$ signal was always less than 15000 cps leading to a negligible contribution of $\mathrm{HD}^{+}$at mass 3.014. This contribution is generally $3-5 \mathrm{cps}$ at mass 3.016 and $<0.1$ at mass 3.014 . Helium standards were repeated between samples to calibrate the mass discrimination and the sensitivity of the mass spectrometer. The helium standard is a gas collected in a spring source from Réunion island (Indian Ocean), with a ${ }^{4} \mathrm{He} /{ }^{3} \mathrm{He}$ ratio of $56,980 \pm 450$ $(\mathrm{R} / \mathrm{Ra}=12.68 \pm 0.10)$. In order to propagate the uncertainties, the standard deviation of all the measured standards during the analysis period was considered. Moreover, samples previously analyzed by M.D. 
Kurz from the Woods Hole Oceanographic Institution were analyzed in Paris in order to check the external reproducibility. These samples are ALV3297-5, ALV3301-4, ALV3527-1 and ALV3791-1. As shown in table 1 , our results agree perfectly with the results obtained at $\mathrm{WHOI}$ for both concentrations and helium isotopic ratios.

\section{Results}

Helium concentration and isotopic ratios are given in table 2 for PACANTARCTIC 2 samples (PAC2). ${ }^{4} \mathrm{He}$ concentrations vary between $1.910^{-8}$ (DR06-6g) and $2.110^{-5} \mathrm{ccSTP} / \mathrm{g}$ (DR33-3g). Except for samples DR06-6g and DR27-1g, the helium concentrations are typical of MORB concentrations [Honda and Patterson, 1999 ; Moreira and Sarda, 2000 ; Sarda and Moreira, 2002]. ${ }^{4} \mathrm{He} /{ }^{3} \mathrm{He}$ ratios vary from 95,071 to $185,268 \pm 52,255$. Except for the latter very high, and un-precise ratio, the highest helium isotopic ratio is observed for sample DR27-1g $(118,450)$. These two radiogenic ratios correspond to the poorest samples in helium. The ${ }^{4} \mathrm{He} /{ }^{3} \mathrm{He}$ variation with latitude is represented in figure 2 (with the exception of samples DR06-6g and DR27-1g). The helium isotopic ratios are similar to the mean MORB ratio, although slightly more radiogenic. The mean PAC2 ratio is $99,725 \pm 2720$ (without samples DR06-6g and DR27-1g for which we will discuss below the origin of their ratios), compared to the mean MORB ratio of 90,000 [Allègre et al., 1995]. Good reproducibility within a single dredge is also observed as illustrated in samples DR33-2g and DR33-3g that show ${ }^{4} \mathrm{He} /{ }^{3} \mathrm{He}$ ratios of $99,524 \pm 1645$ and $98,843 \pm 1487$ respectively.

\section{Discussion}

The radiogenic samples DR6-6 and DR27-1

Samples DR6-6g and DR27-1g present low helium concentration for MORB samples $\left(1.910^{-8}\right.$ and 1.9 $10^{-7} \mathrm{ccSTP} / \mathrm{g}$ respectively) as well as radiogenic helium isotopic ratio $(185,268 \pm 52255$ and $118,450 \pm 7767)$ compared to other MORB from the area. The Th and $U$ concentrations are 0.95 and $0.30 \mathrm{ppm}$ for DR6-6g and 1.41 and $0.43 \mathrm{ppm}$ for DR27-1g respectively. These concentrations are relatively high for MORB samples and also higher than found in MORB from the area [Hamelin et al., 2007]. These latter facts are related to the observation that these two samples are more evolved than the other samples from the area Indeed, these two samples present higher alkalis and $\mathrm{SiO}_{2}$ contents and lower $\mathrm{MgO}$ than the other [Hamelin et al., 2007].

Considering the "He production equation,-we can derive an "eruption age" if we assume that the radiogenic helium is post eruptive. Samples were melted and therefore the helium is the sum of mantle and radiogenic helium present in the sample. With an initial ${ }^{4} \mathrm{He} /{ }^{3} \mathrm{He}$ ratio similar to the mean ratio of the other MORB from this area, $(99,730)$, and using the measured $U$ and Th content, we get 140,000 and 330,000 years for samples DR6-6g and DR27-1g respectively, suggesting that the postdegassing radiogenic ingrowth is responsible for the radiogenic isotopic ratios. Note that these ages are minimum since helium diffusion can occur. In the following discussion, we will then ignore these two samples.

The mean isotopic ratio: the "normal" MORB ratio?

The homogeneity of the helium isotopic ratio over more than $1200 \mathrm{~km}$ of mid oceanic ridge is clear. This part of the global ridge system is the most homogeneous for the helium isotopic ratio [Allègre et al., 1995 ; Georgen et al., 2003]. No oceanic island chain and topographic anomaly are present in the area. The closest hotspot that can be attributed to a mantle plume is the Foundation seamount chain, which crosses the Pacific Antarctic ridge at $\sim 37.5^{\circ} \mathrm{S}$ [Maia et al., 2005]. We can therefore assume that the mean ratio determined on the PAC2 samples represent the "normal" helium isotopic ratio for the pacific MORB source mantle.

The difference between South and North of Menard Transform zone.

Figure 2 shows that the Menard T.F. is a natural boundary of the mantle convection. A difference in the ${ }^{4} \mathrm{He} /{ }^{3} \mathrm{He}$ ratio can be observed. The mean isotopic ratios are 96,595 \pm 1520 (1s) and 100,347 \pm 2330 (1s) for the south and for the north zones of Menard T.F., respectively (samples DR6-6g and DR27-1g 
are not considered). In order to evaluate the possibility that the difference in the mean helium isotopic ratio between the two ridge segments reflects different mantle histories, including degassing or depletion during melting, we have developed a simple mantle evolution model that considers helium degassing and radiogenic production of ${ }^{4} \mathrm{He}$. The equations that govern the evolution of ${ }^{3} \mathrm{He},{ }^{4} \mathrm{He}$ and ${ }^{4} \mathrm{He} /{ }^{3} \mathrm{He}$ are the following:

$$
\frac{d^{3} \mathrm{He}}{d \tau}=+\phi^{3} \mathrm{He}
$$

$$
\begin{aligned}
& \frac{d^{4} H e}{d \tau}=+\phi^{4} H e-8 \lambda_{8}{ }^{238} U_{A} e^{\lambda_{8} \tau}-7 \lambda_{5}{ }^{235} U_{A} e^{\lambda_{5} \tau}-6 \lambda_{2}{ }^{232} T h_{A} e^{\lambda_{2} \tau} \\
& R(\tau)=R_{A}-\frac{8 \frac{\lambda_{8}}{\lambda_{8}-\phi}{ }^{238} U_{A}\left[e^{\left(\lambda_{8}-\phi\right) \tau}-1\right]+7 \frac{\lambda_{5}}{\lambda_{5}-\phi}{ }^{235} U_{A}\left[e^{\left(\lambda_{5}-\phi\right) \tau}-1\right]+6 \frac{\lambda_{2}{ }^{232}}{\lambda_{2}-\phi} h_{A}\left[e^{\left(\lambda_{2}-\phi\right) \tau}-1\right]}{{ }^{3} H e_{A}}
\end{aligned}
$$

where $R(\tau)$ is the isotopic ratio, $R_{A}$ is the present-day isotopic ratio and $\Phi$ is a constant (degassing constant in $\left.\mathrm{yr}^{-1}\right)$. These equations are given as a function of age $(\tau)$. The letter $\mathrm{A}$ stands for present. The global ${ }^{3} \mathrm{He}$ flux at ridges is $1000 \mathrm{~mol} /$ year [Farley et al., 1995], which corresponds to $\mathrm{d}^{3} \mathrm{He} / \mathrm{dt}$. Therefore, knowing the mass of the degassing mantle, and the mean concentration of ${ }^{3} \mathrm{He}$ in the mantle, one can get the mean degassing rate of the mantle $\Phi$. Assuming that the popping rock $2 \pi D 43$ reflects undegassed magma [Moreira et al., 1998], and that the melting rate is $\sim 10 \%$ one can get $\left[{ }^{3} \mathrm{He}\right] \sim 10^{-10} \mathrm{cc} / \mathrm{g}$. Therefore, $\Phi=2.210^{-10} \mathrm{yr}^{-1}$ if the degassing mantle is the upper mantle $\left(\mathrm{m}=10^{27} \mathrm{~g}\right)$. If one considers that the popping rock $2 \pi \mathrm{D} 43$ is an exceptionally gas rich sample, helium concentration in the mantle should be lower. Therefore, we also did the calculations with a $\left[^{3} \mathrm{He}\right]$ of $510^{-11} \mathrm{cc} / \mathrm{g}$. We assume the degassing constant is the same for each ridge segment, including south and north of Menard T.F. as this constant reflects only the oceanic crust formation rate. Two isotopic ratios, at identical ages, to be different, have to have different $\mathrm{U} /{ }^{3} \mathrm{He}$ ratio. In order to get separation of the two mantles since $500 \mathrm{My}$ (Figure 3), the difference in the $\mathrm{U} /{ }^{3} \mathrm{He}$ ratio should be 1.38 or 1.26 depending of the helium concentration. If the separation occurred $1 \mathrm{Ga}$ ago, smaller differences are required. For the calculation, the Th/U ratio was taken as 2.66 and 2.31 for the south and north segments respectively. These values are the mean value of all the samples. The mean uranium content appears to be the same $(0.11$ and $0.10 \mathrm{ppm})$. Using $10 \%$ melting we can estimate the $U$ content of the mantle as 10ppb. The most radiogenic mantle was probably either more degassed or less depleted in $U$ by a factor of $1.2-1.4$, even if it is not clear from the data, especially for helium. Helium concentration in MORB is not directly proportional to the inverse of melting rate like for non volatile elements, since degassing at the surface is susceptible to change the helium content by a few orders of magnitudes [Moreira and Allègre, 2002]. Neon and argon measurements are necessary to quantify the degassing process [Moreira and Sarda, 2000 ; Sarda and Moreira, 2002] .

As a matter of fact, other isotopic tracers show a difference between south and north of Menard T.F. [Hamelin et al., 2007]. For example, the ${ }^{87} \mathrm{Sr} /{ }^{86} \mathrm{Sr}$ of the south segment is slightly less radiogenic $(\sim 0.7024)$ than the north segment $(\sim 0.7025)$, suggesting a difference in the ${ }^{87} \mathrm{Rb} /{ }^{86} \mathrm{Sr}$ fractionation history.

Correlation between spreading rate and ${ }^{4} \mathrm{He} /{ }^{3} \mathrm{He}$ standard deviation.

Using the same methodology as described in [Allègre et al., 1995] for the calculation of the standard deviation, e.g. $\langle\alpha\rangle$ can be calculated using:

$$
(n-1)<\alpha>^{2}=\sum\left[\sigma_{i}^{2}+\left(X_{i}-X_{m}\right)^{2}\right]
$$

where $\sigma_{i}$ is the individual uncertainty on the ${ }^{4} \mathrm{He} /{ }^{3} \mathrm{He}$ ratio, $X_{i}$ is the measured ${ }^{4} \mathrm{He} /{ }^{3} \mathrm{He}$ and $X_{m}$ is the mean ratio (weighted for uncertainties). For PAC2 samples, the mean pondered ${ }^{4} \mathrm{He} /{ }^{3} \mathrm{He}$ ratio is 99,173 and $\langle\alpha\rangle=3371$. The mean spreading rate of the studied segment is $9 \mathrm{~cm} / \mathrm{year}$, which is one of 
the fastest among all the mid oceanic ridges. Therefore, our new set of data is consistent with the correlation between $\langle\alpha\rangle$ and the inverse of the spreading rate observed by Allègre et al. [Allègre et al., 1995]. This correlation was interpreted as the result of a better mixing of the MORB source when the spreading rate is high and assumed to directly represent the vigor of the mantle convection.

\section{Conclusions}

The Pacific-Antarctic Ridge between 41.5 and $52.5^{\circ} \mathrm{S}$ presents the most homogeneous helium isotopic ratio among the worldwide ridge system. This can be interpreted in two ways. The first one is that this part of the ridge is free from any mantle plume that can "influence" the asthenospheric mantle. The relatively high spreading rate reflects large melting, and therefore more homogeneous mantle zone, than for slower mid oceanic ridges such as the South West Indian Ridge or North Atlantic. Moreover, the Menard fracture zone appears to separate two mantles with slightly different helium isotopic ratio, suggesting a different history for each of these two mantles, including degassing or incompatible element depletion (in particular $U$ and $\mathrm{Th}$ ) at least more than 500 My ago.

\section{Acknowledgments}

The authors wish to thank the captain Michel Houmard, the crew of the R/V L'Atalante and the scientific team for their help during the PACANTARCTIC 2 cruise. C. Hamelin is thanked for the comments on the manuscript. Mark Kurz is thanked for the Alvin samples and for unpublished data allowing an inter-laboratory calibration. This is IPGP contribution number 2346.

\section{References}

Allègre, C. J., et al. (1995), 4He/3He dispersion and mantle convection, Geophysical Research Letters, 22(17), 2325-2328.

Allègre, C. J., and M. Moreira (2004), Rare gas systematics and the origin of oceanic islands: the key role of entrainment, Earth and Planetary Science Letters, 228, 85-92.

Dosso, L., et al. (2005), The Pacific-Antarctic Ridge between $41^{\circ} 15^{\prime} \mathrm{S}$ and $52^{\circ} 45^{\prime} \mathrm{S}$ : survey and sampling during the PACANTARCTIC2 cruise., InterRidge News, 14, 1-4.

Farley, K. A., et al. (1995), Constraints on mantle $3 \mathrm{He}$ fluxes and deep-sea circulation from an oceanic general circulation model, J. Geophys. res., 100, 3829-3839.

Georgen, J. E., et al. (2003), low $3 \mathrm{He} / 4 \mathrm{He}$ ratios in basalt glasses from the western Southwest Indian Ridge (10-24 $\left.{ }^{\circ}\right)$, Earth Planet. Sci. Lett., 206, 509-528.

Hamelin, C., et al. (2007), Geochemical morphology of the Pacific-Antartic Ridge between 41 and $53^{\circ} \mathrm{S}$, Earth and Planetary Science Letters, submitted.

Hilton, D. R., et al. (1999), Extreme $3 \mathrm{He} / 4 \mathrm{He}$ ratios in northwest Iceland: constraining the common component in mantle plumes, Earth. Planet. Sci. Lett., 173, 53-60.

Honda, M., and D. B. Patterson (1999), Systematic elemental fractionation of mantle-derived helium, neon, and argon in mid-oceanic ridge glasses, Geochim. Cosmochim. Acta, 63, 2863-2874.

Klingelhoefer, F., et al. (2006), New structural and geochemical observations from the Pacific-Antarctic Ridge between $52^{\circ} 45^{\prime}$ S and $41^{\circ} 15^{\prime}$ S, Geoph. Res. Lett., 33.

Kurz, M. D., et al. (1982), Helium isotopic systematics of oceanic islands and mantle heterogeneity, Nature, 297, 43-47.

Maia, M., et al. (2005), Constraints on age and construction process of the Foundation chain submarine volcanoes from magnetic modeling, Earth and Planetary Science Letters, 235, 183-199.

Moreira, M., et al. (1998), Rare gas systematics on popping rock : estimates of isotopic and elemental compositions in the upper mantle, Science, 279, 1178-1181.

Moreira, M., et al. (1999), Helium and lead isotope geochemistry in the Azores archipelago, Earth Planet. Sci. Lett., 169, 189-205.

Moreira, M., and P. Sarda (2000), Noble gas constraints on degassing processes, Earth Planet. Sci. Lett., 176, 375-386.

Moreira, M., and C. J. Allègre (2002), Rare gas systematics on Mid Atlantic Ridge $\left(37^{\circ}-40^{\circ}\right)$, Earth Planet. Sci. Lett., 198, 401-416.

Sarda, P., and M. Moreira (2002), Vesiculation and vesicle loss in Mid Oceanic Ridge basalt glasses: $\mathrm{He}, \mathrm{Ne}, \mathrm{Ar}$ elemental fractionation and pressure influence, Geochem. Cosmoch. Acta, 66, 1449-1458. 
Schilling, J. G. (1985), Upper mantle heterogeneity and dynamics, Nature, 314, 62-67.

Schilling, J. G. (1991), Fluxes and excess temperatures of mantle plumes inferred from their interaction with migrating mid-ocean ridges, Nature, 352, 397-402.

Stuart, F. M., et al. (2003), High $3 \mathrm{He} / 4 \mathrm{He}$ ratios in picritic basalts from Baffin Island and the role of a mixed reservoir in mantle plumes, Nature, 424, 57-59.

\section{Tables}

Table 1

\begin{tabular}{llllllll}
\hline Sample & Weight $(\mathrm{g})$ & ${ }^{4} \mathrm{He}(\mu \mathrm{cc} / \mathrm{g})$ & $\mathrm{R} / \mathrm{Ra}_{\text {Paris }}$ & \pm & ${ }^{4} \mathrm{He}(\mu \mathrm{cc} / \mathrm{g})$ & $\mathrm{R} / \mathrm{Ra}$ wHOI & \pm \\
\hline ALV 3297-5 & 0.545 & 16 & 9.3 & 0.1 & 17 & 9.26 & 0.05 \\
ALV 3297-5 & 0.132 & 18 & 9.4 & 0.2 & 17 & 9.26 & 0.05 \\
ALV 3301-4 & 0.297 & 20 & 9.5 & 0.1 & 21 & 9.50 & 0.06 \\
ALV 3301-4 & 0.136 & 21 & 9.4 & 0.2 & 21 & 9.50 & 0.06 \\
ALV 3527-1 & 0.218 & 19 & 8.5 & 0.2 & 22 & 8.39 & 0.04 \\
ALV 3791-1 & 0.366 & 8.3 & 8.2 & 0.2 & 8.3 & 8.31 & 0.06 \\
\hline
\end{tabular}

Table 1: Comparison of helium content and isotopic ratio of some samples analyzed in Paris and at WHOI by M. Kurz. These results illustrate the good inter-laboratory reproducibility for both helium concentration and isotopic ratios.

Table 2

\begin{tabular}{llllllllll}
\hline Sample & Weight & Lat & Long & Depth & $\begin{array}{l}{ }^{4} \mathrm{He} \\
(\mu \mathrm{CCSTP} / \mathrm{g})\end{array}$ & $\mathrm{R} / \mathrm{Ra}$ & \pm & ${ }^{4} \mathrm{He} /{ }^{3} \mathrm{He}$ & \pm \\
\hline PAC2 DR01-2g & 0.319 & 52.53 & 118.35 & 2337 & 15.0 & 7.6 & 0.1 & 95071 & 1251 \\
PAC2 DR03-1g & 0.235 & 51.80 & 117.97 & 2366 & 14.0 & 7.5 & 0.1 & 96339 & 1285 \\
PAC2 DR04-2g & 0.198 & 51.43 & 117.77 & 2376 & 16.0 & 7.6 & 0.2 & 95071 & 2502 \\
PAC2 DR05-3g & 0.407 & 50.97 & 117.40 & 2800 & 5.3 & 7.5 & 0.2 & 96468 & 2447 \\
PAC2 DR06-6g & 0.505 & 50.7 & 117.19 & 2651 & 0.019 & 3.9 & 1.1 & 185268 & 52255 \\
PAC2 DR07-2g & 0.701 & 50.24 & 117.05 & 2220 & 6.7 & 7.4 & 0.1 & 97641 & 1715 \\
PAC2 DR08-1g & 0.582 & 50.00 & 116.97 & 2230 & 9.7 & 7.3 & 0.1 & 98979 & 1356 \\
PAC2 DR20-1g & 0.693 & 49.73 & 113.78 & 2440 & 12.0 & 7.1 & 0.1 & 101767 & 1433 \\
PAC2 DR21-2g & 0.098 & 49.25 & 113.60 & 2347 & 15.0 & 7.1 & 0.1 & 101624 & 2001 \\
PAC2 DR22-1g & 0.363 & 48.73 & 113.35 & 2413 & 15.0 & 7.3 & 0.1 & 99661 & 1512 \\
PAC2 DR27-1g & 0.238 & 48.18 & 113.34 & 2359 & 0.19 & 6.1 & 0.4 & 118450 & 7767 \\
PAC2 DR28-1g & 0.385 & 47.51 & 113.24 & 2450 & 15.0 & 7.1 & 0.1 & 102054 & 1874 \\
PAC2 DR29-1g & 0.242 & 47.00 & 113.08 & 2400 & 8.9 & 7.2 & 0.2 & 100633 & 2803 \\
PAC2 DR30-1g & 0.314 & 46.40 & 112.87 & 2340 & 8.8 & 6.8 & 0.1 & 106885 & 2214 \\
PAC2 DR31-1g & 0.491 & 45.85 & 112.68 & 2400 & 14.0 & 7.3 & 0.1 & 99114 & 1632 \\
PAC2 DR32-1g & 0.120 & 45.40 & 112.42 & 2400 & 12.0 & 7.2 & 0.2 & 100214 & 2224 \\
PAC2 DR33-2g & 0.341 & 44.88 & 112.25 & 2373 & 18.0 & 7.3 & 0.1 & 99524 & 1645 \\
PAC2 DR33-3g & 0.183 & 44.88 & 112.25 & 2373 & 21.0 & 7.3 & 0.1 & 98843 & 1487 \\
PAC2 DR34-1g & 0.179 & 44.24 & 112.03 & 2422 & 19.0 & 7.3 & 0.1 & 98439 & 1743 \\
PAC2 DR35-1Ag & 0.394 & 43.59 & 111.75 & 2460 & 16.0 & 7.2 & 0.1 & 99799 & 1654 \\
PAC2 DR36-1g & 0.299 & 42.95 & 111.55 & 2500 & 17.0 & 7.5 & 0.2 & 96211 & 2690 \\
PAC2 DR37-2g & 0.101 & 42.27 & 111.33 & 2457 & 3.4 & 7.3 & 0.2 & 99661 & 2337 \\
PAC2 DR38-1g & 0.693 & 41.80 & 111.27 & 2475 & 4.4 & 7.2 & 0.1 & 100773 & 1827 \\
\hline
\end{tabular}

Table 2: Helium content and isotopic ratios of PacAntarctic 2 samples. $\mathrm{Ra}$ is the ${ }^{3} \mathrm{He} /{ }^{4} \mathrm{He}$ ratio of the atmosphere $\left(=1.38410^{-6}\right)$. 


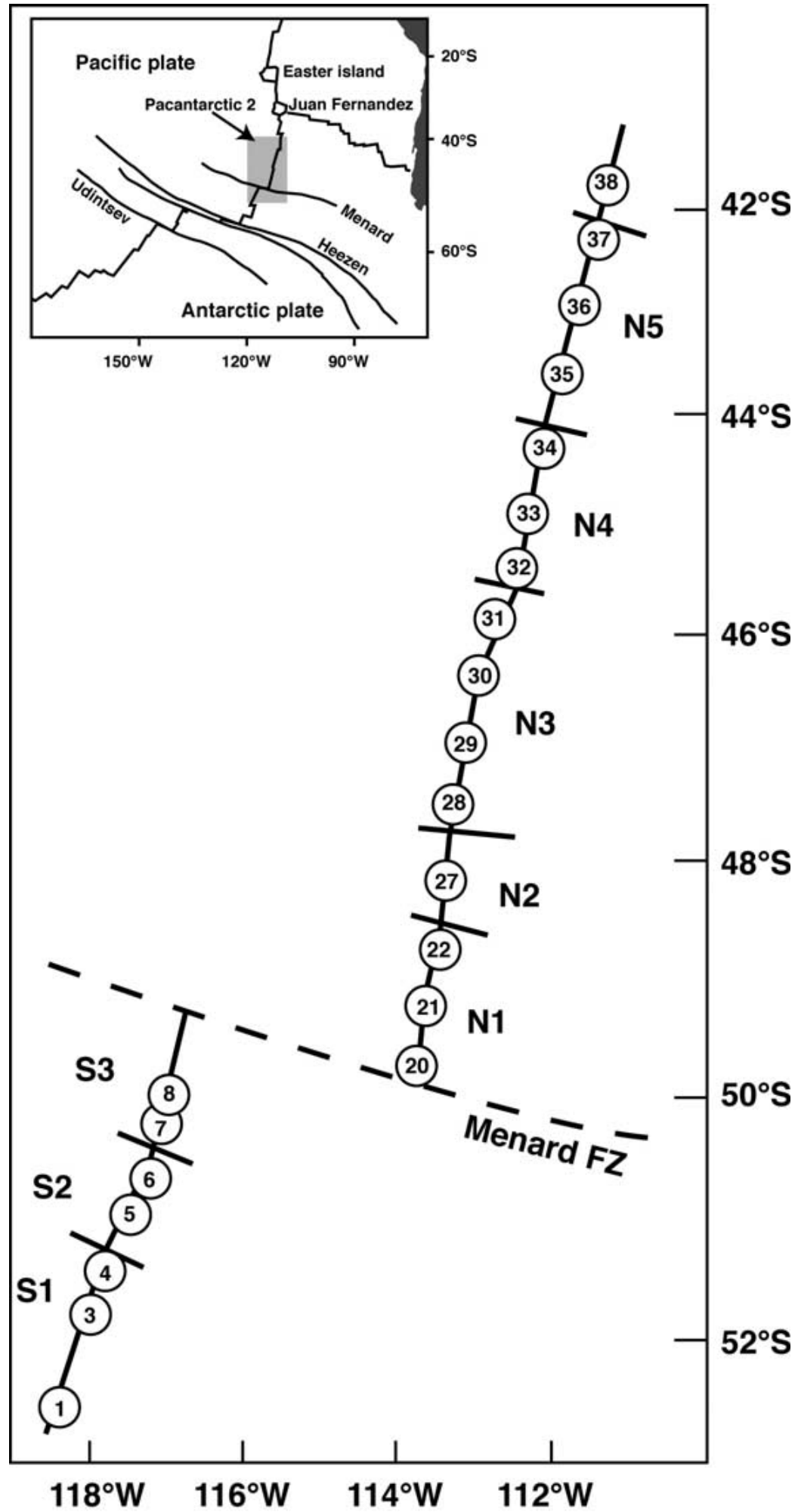

Figure 1: Sample locations. Numbers inside circles are dredge numbers (e.g. DR5, DR6, ...). S1-3 and N1-5 are segment numbers as defined in [Klingelhoefer et al., 2006] based on the ridge morphology. Insert represents the studied area in the South Pacific. Figure is derived from [Dosso et al., 2005]. 


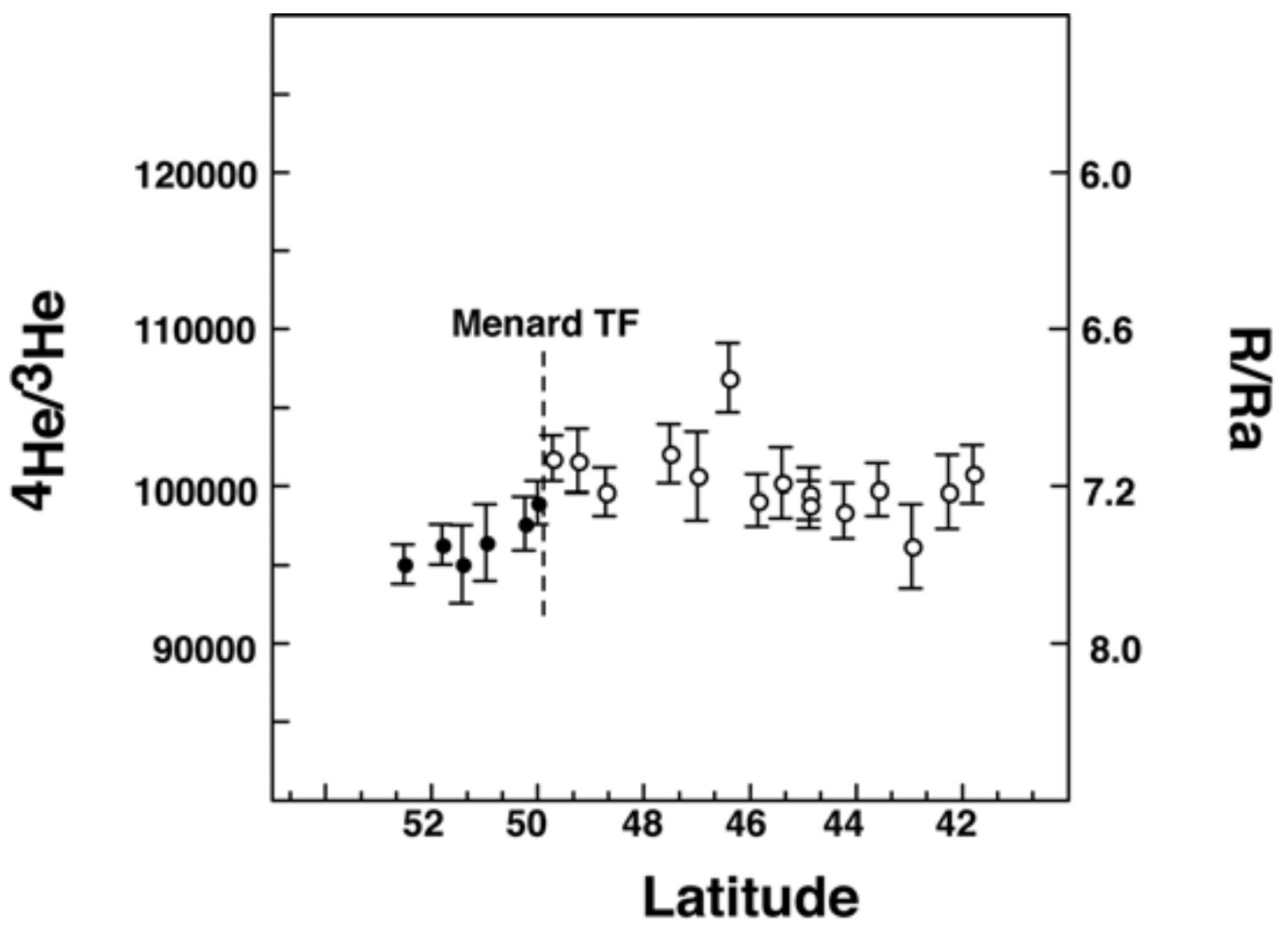

Figure 2: Helium isotopic ratio variation with latitude along the Pacific-Antarctic ridge. The Menard Fracture zone appears to be a boundary between two distinct mantles.

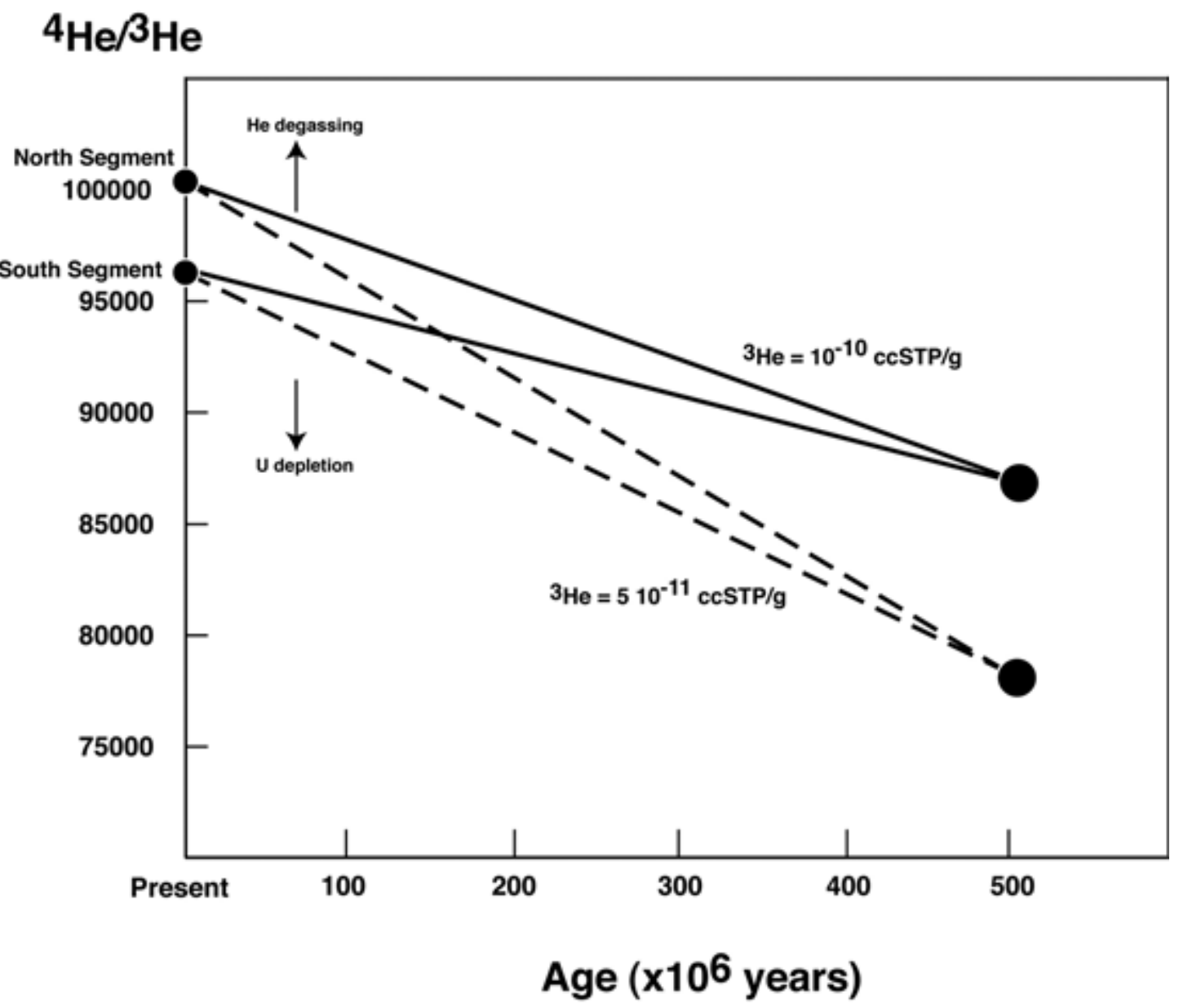


Figure 3: Helium isotopic evolution for two isolated mantles that degas with the same rate. We assume here that the $\mathrm{U} /{ }^{3} \mathrm{He}$ fractionation occurred $\sim 500 \mathrm{My}$ ago. In order to get the observed difference in the helium isotopic ratio, an $\mathrm{U} /{ }^{3} \mathrm{He}$ fractionation of $\sim 1.4$ or 1.26 depending of the helium concentration, is required. This can be interpreted either as a higher degassing of ${ }^{3} \mathrm{He}$ or a depletion in $\mathrm{U}$. The calculations are done with two different ${ }^{3} \mathrm{He}$ concentrations $\left(10^{-10} \mathrm{ccSTP} / \mathrm{g}\right.$ [Moreira et al., 1998] and 5 $10^{-11} \mathrm{ccSTP} / \mathrm{g}$, which assumes the popping rock $2 \pi \mathrm{D} 43$ is exceptionally gas rich ). 